\title{
Soft Nitrogen and Sulfur Incorporated into Enzymatic Hydrolysis Lignin as an Environmentally Friendly Antioxidant and Mercury Adsorbent
}

\author{
Wen-Xin Huang, Yu-Hua Zhang, Yuan-Yuan Ge, ${ }^{*}$ Li Qin, and Zhi-Li Li* \\ Soft donors of nitrogen and sulfur were incorporated into enzymatic \\ hydrolysis lignin (EHL-NS) to make it suitable for multiple applications. \\ Characterizations of the environmentally friendly material by Fourier \\ transform infrared spectroscopy, scanning electron microscopy, energy \\ dispersive spectroscopy, and thermogravimetric analysis confirmed the \\ layered porous structure with nitrogen and sulfur groups. It exhibited high \\ antioxidant activity due to the strong electron-donating capability of the \\ soft donors. Moreover, the soft donors also contributed to the chemical \\ complexation of $\mathrm{Hg}$ (II) with EHL-NS, which distinctly enhanced the \\ adsorption of $\mathrm{Hg}(\mathrm{II})$ in water $\left(Q_{\mathrm{e}}=180 \mathrm{mg} / \mathrm{g}, 25^{\circ} \mathrm{C}\right)$. Given that the free \\ radicals were highly effective at scavenging and adsorption, the \\ functionalized enzymatic hydrolysis lignin is expected to serve a useful \\ role.
}

Keywords: Lignin; Natural polymer; Antioxidant; Adsorption; Mercury

Contact information: School of Chemistry and Chemical Engineering, Guangxi University, Nanning, 530004, China; *Corresponding authors: geyy@gxu.edu.cn; lizhili@gxu.edu.cn

\section{INTRODUCTION}

The design of green materials using biomass has attracted increased attention due to the depletion of fossil resources and environmental concerns (Thakur et al. 2014). Lignin, the second most abundant biomass in the world, has many potential applications in polymers (Thakur et al. 2014), but it must be separated from the plant before its utilization. Compared with the conventional alkaline pulping process, enzymatic hydrolysis of lignocellulose uses mild conditions and is considered a clean and green method. It has been predicted that the US bio-refinery industry will generate an estimated $60 \mathrm{Mt}$ of enzymatic hydrolysis lignin (EHL) annually by 2022 (Bugg and Rahmanpour 2015). Hence, the exploitation of this material is crucial for improving the economics of the bio-refinery industry.

Increasing interest in antioxidants from lignins to prevent radical attack, as well as for use as adsorbents for water purification has been observed (Salanti et al. 2010; Li et al. 2015a; Li et al. 2017). For example: Li et al. (2015b) prepared a new lignin xanthate resin (LXR) from alkaline lignin. The incorporation of xanthate functional groups (-CSS ${ }^{-}$) onto lignin matrix enhanced its interaction with $\mathrm{Pb}(\mathrm{II})$ and adsorption capacity, which is 64.9 $\mathrm{mg} / \mathrm{g}$ at $30^{\circ} \mathrm{C}, 4.8$ times higher than the original lignin. Ge et al. (2014) developed a ligninbased dithiocarbamate (LDTC) by anchoring $-\mathrm{NCSS}^{-}$to the alkaline lignin matrix. Due to the cross-linked polymer matrix, high content of -NCSS${ }^{-}$groups, the LDTC showed a high adsorption amount of $175.9 \mathrm{mg} / \mathrm{g}$ for $\mathrm{Cu}(\mathrm{II})$ at $25^{\circ} \mathrm{C}$. Moreover, the resultant metal-loaded 
solid bio-sorbents were firstly estimated as free radical scavengers due to the inherent merits of naturally occurring polyphenols, which therefore could provide a potential way for value-added usage of the material. However, due to lack of functionality, there has been little research into advanced materials generated from EHL. The combination of soft sulfur and nitrogen represents a potentially powerful strategy for multi-functionality that utilizes their strong electron-donating abilities (Kundu and Bhaumik 2016). In this study, functionalized EHL with soft nitrogen and sulfur (EHL-NS) was designed to enhance its antioxidant activity and to improve its adsorption of metal ions.

\section{EXPERIMENTAL}

\section{Materials}

EHL was provided by Longli Biotech Co., China. It was purified before usage with the method by Li et al. (2011). Diethylenetriamine (DETA), $\mathrm{CS}_{2}$, formaldehyde (37\%), methanol, and $\mathrm{Hg}\left(\mathrm{NO}_{3}\right)_{2}$ were purchased from Guanghua Chem. Co. (Guangzhou, China). The 2,2-diphenyl-1-picrylhydrazyl radical (DPPH) was purchased from Sigma-Aldrich (Shanghai, China).

\section{EHL-NS Synthesis}

A total of $8.0 \mathrm{~g} \mathrm{EHL}$ and $7.0 \mathrm{~mL}$ DETA were added to $120 \mathrm{~mL}$ of water $(\mathrm{pH} \mathrm{12})$ by stirring at $120 \mathrm{rpm}$. Next, $9.4 \mathrm{~mL}$ of formaldehyde was added dropwise, and the mixture was subjected to microwave heating (XH-MC-1, $300 \mathrm{~W}, 25 \mathrm{~min}$ ). After cooling to $40{ }^{\circ} \mathrm{C}$, $7.8 \mathrm{~mL}$ of $\mathrm{CS}_{2}$ was added for $2 \mathrm{~h}$ of esterification. The product was obtained by filtration, washing with deionized water, and drying under a vacuum at $50{ }^{\circ} \mathrm{C}$ for $24 \mathrm{~h}$, which was named as EHL-NS (purity 95.2\%).

\section{Analysis}

The surface morphology was identified using a Hitachi S-340 scanning electron microscope (SEM) (Tokyo, Japan, $20 \mathrm{kV}$, and $\times 1.00 \mathrm{k}$ ) with energy dispersive spectroscopy (EDS) by immobilizing the sample with conductive glue. Fourier transform infrared spectroscopy (FTIR) was conducted with a Nexus 470 (Nicolet Instruments, Offenbach, Germany) in the range of 500 to $4000 \mathrm{~cm}^{-1}$ by the $\mathrm{KBr}$ pellet method. Thermogravimetric analysis (TGA) was conducted with a Netzsch STA449C $\left(10{ }^{\circ} \mathrm{C} \mathrm{min}{ }^{-1}, \mathrm{~N}_{2} 10 \mathrm{~mL} \mathrm{~min}{ }^{-1}\right)$ (NETZSCH, Germany). The Brunauer-Emmett-Teller surface area $\left(S_{\mathrm{BET}}\right)$ was measured with a Quadrasorb SI analyzer (Quantachrome, Boynton, USA), the total pore volume ( $V_{\mathrm{p}}$, $\left.\mathrm{cm}^{3} / \mathrm{g}\right)$ and average pore size $\left(d_{\mathrm{p}}, \mathrm{nm}\right)$ of the samples were also determined.

Radicals scavenging activity (RSA) was determined by the DPPH method using a Shimadzu UV-2101PC spectrophotometer at $\lambda_{\max }=520 \mathrm{~nm}$ (Kyoto, Japan) (Salanti et al. 2010). The inhibition of DPPH (\%) was calculated as follows,

$$
R S A(\%)=\left[\left(A_{0}-A_{1}\right) / A_{0}\right] \times 100
$$

where $A_{0}, A_{1}$ is the absorbance of the DPPH solution with and without the antioxidants.

The adsorption of $\mathrm{Hg}(\mathrm{II})$, one of the most toxic heavy metals, was used as a model metal ion. EHL-NS was tested by a batch-wise mode in one set of $100-\mathrm{mL}$ conical flasks. The adsorbent was added to each flask containing $\mathrm{Hg}(\mathrm{II})$ solution with different 
concentrations. The mixtures were stirred at 10,25 , and $40{ }^{\circ} \mathrm{C}$ for a period, and then the supernatants were taken out and filtered $(0.22 \mu \mathrm{m})$ and analyzed by inductively coupled plasma optical emission spectrometry (ICP-OES; Optima 5300DV, Perkin-Elmer, Waltham, MA, USA). All experiments were carried out in triplicate with the relative deviations of $<5 \%$.

\section{RESULTS AND DISCUSSION}

\section{Characterization}

The SEM images show that EHL displayed a compact surface with irregular blocks (Fig. 1a), while EHL-NS contained various micro-scale interstitial spaces, indicating a layered porous structure (Fig. 1b). The layered porous structure resulted in a higher $S_{\mathrm{BET}}$ of EHL-NS $\left(3.9 \mathrm{~m}^{2} \mathrm{~g}^{-1}\right)$ than EHL $\left(2.9 \mathrm{~m}^{2} \mathrm{~g}^{-1}\right)$, as determined by the BET method. The average pore size and total pore volume of EHL-NS $\left(d_{\mathrm{p}}=16.4 \mathrm{~nm}, V_{\mathrm{p}}=0.016 \mathrm{~cm}^{3} \mathrm{~g}^{-1}\right)$ were also higher than EHL $\left(d_{\mathrm{p}}=13.8 \mathrm{~nm}, V_{\mathrm{p}}=0.011 \mathrm{~cm}^{3} \mathrm{~g}^{-1}\right)$ that suggested the presence of mesopores in EHL-NS. The EDS results (Fig. 1c) showed obvious signals of N $(0.392 \mathrm{keV})$ and $\mathrm{S}(2.307 \mathrm{keV})$ in EHL-NS.
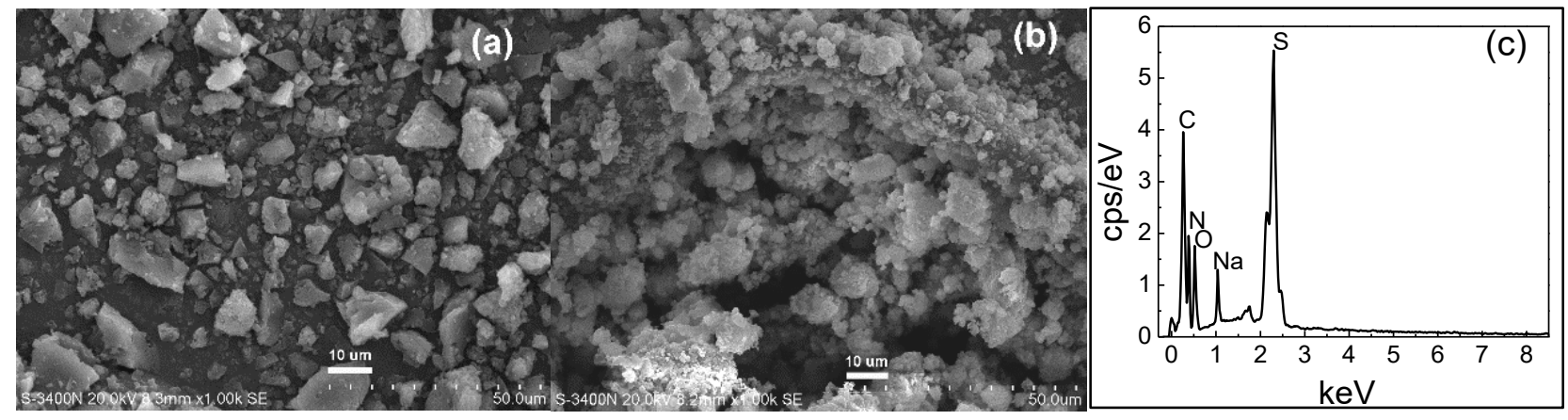

Fig. 1. SEM images of EHL (a) and EHL-NS (b) at magnification of $1 \mathrm{k}$ and EDS spectrum of EHL-NS (c).

(a)

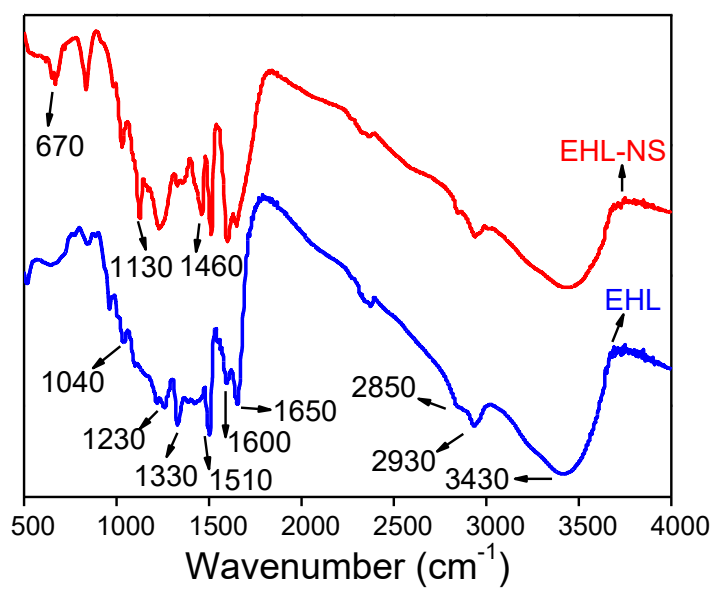

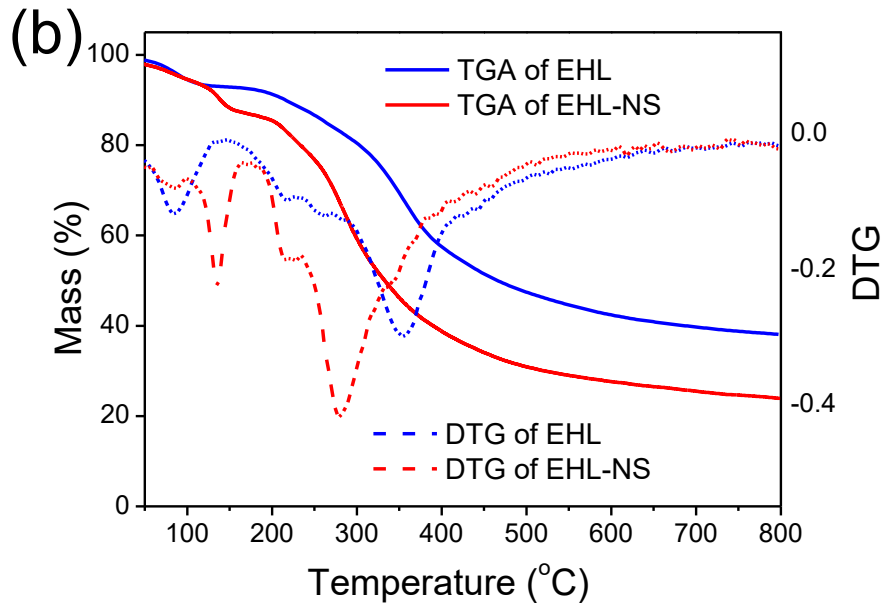

Fig. 2. FTIR spectra (a); TGA (b) of EHL and EHL-NS 
FTIR spectra (Fig. 2a) confirmed the incorporation of $\mathrm{N}$ and $\mathrm{S}$ in EHL-NS. For example, the bands at 1130 and $670 \mathrm{~cm}^{-1}$ indicated the stretching vibrations of $\mathrm{C}=\mathrm{S}$ and $\mathrm{C}$ $\mathrm{S}$ (Qin et al. 2017), respectively; the band at $1460 \mathrm{~cm}^{-1}$ indicated the stretching vibration of C-N (Ge et al. 2014). As shown by the TGA curves (Fig. 2b), the weight loss of EHL was attributed to the vaporized water ( greater than $200{ }^{\circ} \mathrm{C}$ ) and lignin decomposition (355 ${ }^{\circ} \mathrm{C}$ ) (Li et al. 2015b). The new sign at $282{ }^{\circ} \mathrm{C}$ indicated the $\mathrm{C}-\mathrm{N}$ and $\mathrm{C}-\mathrm{S}$ bonds decomposing in EHL-NS.

\section{Antioxidant Activity}

The antioxidant activities are given in Fig. 3. EHL-NS exhibited a higher antioxidant activity, which was indicated by a lower IC50 $\left(25 \mu \mathrm{g} \mathrm{mL}^{-1}\right)$ than EHL $(32 \mu \mathrm{g}$ $\mathrm{mL}^{-1}$ ). The EHL-NS exhibited higher antioxidant activity than EHL due to the incorporation of soft $\mathrm{N}$ and $\mathrm{S}$ into the lignin matrix, which increased the electron-donating capabilities and therefore enhanced the antioxidant activity (Kundu and Bhaumik 2016).

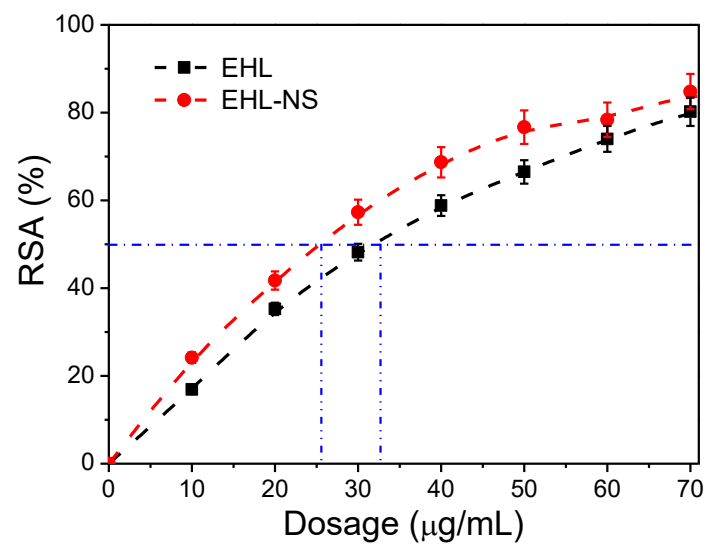

Fig. 3. Radicals scavenging activity of EHL and EHL-NS

\section{Adsorption}

The adsorption kinetics of $\mathrm{Hg}$ (II) on EHL-NS are shown in Fig. 4(a) (dosage 0.2 $\mathrm{g} / \mathrm{L}, \mathrm{pH} 6,25^{\circ} \mathrm{C}$ ). The $Q_{\mathrm{e}}$ increased sharply during the first $20 \mathrm{~min}$ and slowed gradually as equilibrium was approached after $50 \mathrm{~min}$. The pseudo-first-order and pseudo-secondorder kinetic models were used to fit the experimental data, as given by (Li et al. 2017),

$$
\begin{aligned}
& \log \left(Q_{e}-Q_{t}\right)=\log Q_{e}-\frac{k_{1} t}{2.303} \\
& \frac{t}{Q_{t}}=\frac{1}{k_{2} Q_{e}^{2}}+\frac{t}{Q_{e}}
\end{aligned}
$$

where $Q_{\mathrm{t}}(\mathrm{mg} / \mathrm{g})$ is the adsorption amount at $t(\mathrm{~min}), Q_{\mathrm{e}}(\mathrm{mg} / \mathrm{g})$ is the equilibrium adsorption amount, $k_{1}\left(\mathrm{~min}^{-1}\right)$, and $k_{2}(\mathrm{~g} /(\mathrm{mg} \mathrm{min}))$ is a constant. As exhibited in Table 1 , fitting using the pseudo-second-order model had a greater correlation coefficient $\left(R^{2}>0.99\right)$, and the calculated $Q_{\mathrm{e}}$ values were close to the experimental values. Therefore, the pseudo-secondorder model fit well to the adsorption kinetics and accordingly indicated the adsorption was based upon chemical interactions. 
(a)

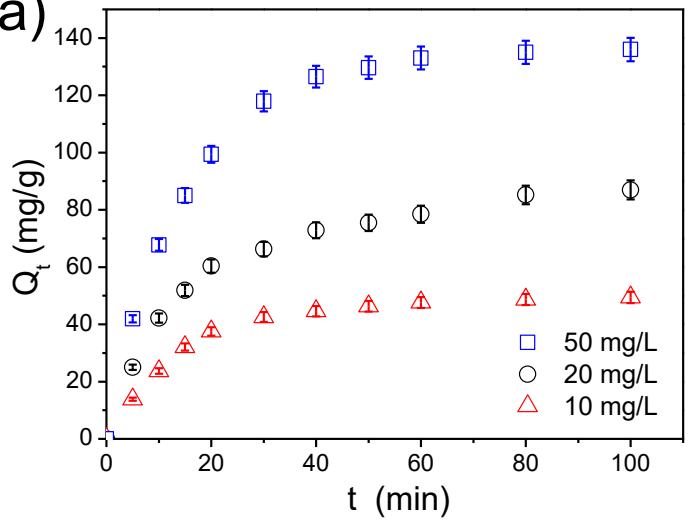

(b)

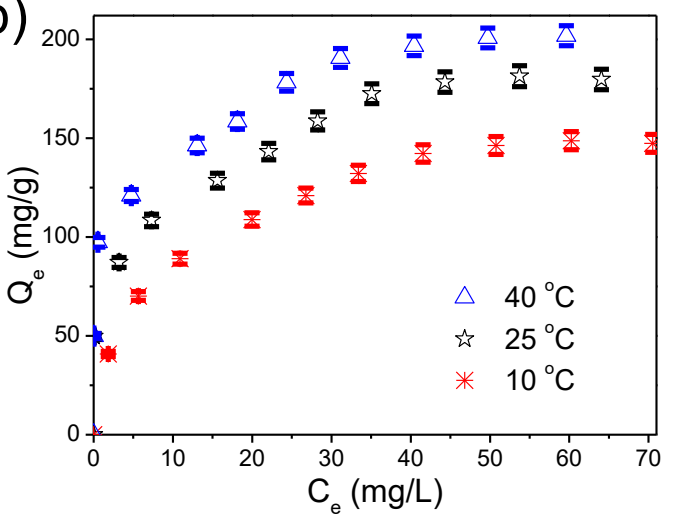

Fig. 4. Adsorption kinetics (a) and isotherms (b) of $\mathrm{Hg}$ (II) on EHL-NS

Table 1. Parameters of the Pseudo-First-Order and Pseudo-Second-Order Models

\begin{tabular}{|c|c|c|c|c|c|c|}
\hline \multirow{2}{*}{$C_{0}(\mathrm{mg} / \mathrm{L})$} & \multicolumn{3}{|c|}{ Pseudo-first-order } & \multicolumn{3}{c|}{ Pseudo-second-order } \\
\cline { 2 - 7 } & $Q_{\mathrm{e}}(\mathrm{mg} / \mathrm{g})$ & $k_{1}\left(\mathrm{~min}^{-1}\right)$ & $R^{2}$ & $Q_{\mathrm{e}}(\mathrm{mg} / \mathrm{g})$ & $k_{2}(\mathrm{~g} /(\mathrm{mg} \mathrm{min}))$ & $R^{2}$ \\
\hline 10 & 48 & 0.07 & 0.998 & 57 & 0.001 & 0.990 \\
\hline 20 & 82 & 0.06 & 0.985 & 97 & 0.0007 & 0.998 \\
\hline 50 & 135 & 0.06 & 0.989 & 159 & 0.0005 & 0.993 \\
\hline
\end{tabular}

The adsorption isotherms are presented in Fig. 4 (b) (dosage $0.2 \mathrm{~g} / \mathrm{L}, \mathrm{pH} 6, t=180$ $\min )$. The $Q_{\mathrm{e}}$ increased with an increasing $C_{\mathrm{e}}$, and the saturated $Q_{\mathrm{e}}$ increased with increasing temperature, which indicated the adsorption was endothermic (Li et al. 2015b). The maximum $Q_{\mathrm{e}}\left(180 \mathrm{mg} / \mathrm{g}, 25^{\circ} \mathrm{C}\right)$ was higher than other biomass-derived adsorbents listed in Table 2. This might be due to the porous structure and incorporated soft $\mathrm{N}$ and $\mathrm{S}$ in the EHL-NS.

Table 2. Adsorption Capacity of Some Biomass-Derived Adsorbents for $\mathrm{Hg}(\mathrm{II})$

\begin{tabular}{|c|c|c|}
\hline Adsorbent & $Q_{\mathrm{e}}(\mathrm{mg} / \mathrm{g})$ & Reference \\
\hline Rice straw & 27.7 & (Rocha et al. 2009) \\
\hline Polyacrylamide-grafted cellulose & 12.5 & (Bicak et al. 1999) \\
\hline Chitosan-thioglyceraldehyde base & 98 & (Monier 2012) \\
\hline Malt rootlets & 50 & (Anagnostopoulos et al. 2012) \\
\hline Chitosan spheres & 31.3 & (Vieira and Beppu 2006) \\
\hline EHL-NS & 180 & this work \\
\hline
\end{tabular}

The isotherms were fitted by the Langmuir and Freundlich models as follows (Freundlich 1906; Langmuir 1918),

$$
\begin{aligned}
& \frac{C_{e}}{Q_{e}}=\frac{C_{e}}{Q_{\max }}+\frac{1}{b Q_{\max }} \\
& \log Q_{e}=\log k_{F}+\frac{1}{n} \log C_{e}
\end{aligned}
$$

where $C_{\mathrm{e}}(\mathrm{mg} / \mathrm{L})$ is the equilibrium concentration; $Q_{\mathrm{m}}$ is the saturated adsorption capacity 
(mg/g); and $b(\mathrm{~L} / \mathrm{mg}), k_{F}(\mathrm{mg} / \mathrm{g})$, and $n$ are constants. As listed in Table 3, the Freundlich model provided better fitting for the greater correlation coefficients $\left(R^{2}>0.98\right)$, indicating the surface of EHL-NS was heterogeneous. The increasing $n$ with temperature indicated the adsorption became more favorable at higher temperature (Li et al. 2015b).

Table 3. Parameters of the Langmuir and Freundlich Models

\begin{tabular}{|c|c|c|c|c|c|c|}
\hline \multirow{2}{*}{$\begin{array}{c}\text { Temperature } \\
\left({ }^{\circ} \mathrm{C}\right)\end{array}$} & \multicolumn{3}{|c|}{ Langmuir } & \multicolumn{3}{c|}{ Freundlich } \\
\cline { 2 - 7 } & $Q_{\mathrm{m}}(\mathrm{mg} / \mathrm{g})$ & $b(\mathrm{~L} / \mathrm{mg})$ & $R^{2}$ & $k_{\mathrm{F}}(\mathrm{mg} / \mathrm{g})$ & $n$ & $R^{2}$ \\
\hline 10 & 165 & 0.12 & 0.986 & 41 & 3.1 & 0.983 \\
\hline 25 & 192 & 0.18 & 0.905 & 73 & 4.4 & 0.983 \\
\hline 40 & 223 & 0.21 & 0.864 & 97 & 5.5 & 0.989 \\
\hline
\end{tabular}

The FTIR spectra of $\mathrm{Hg}$ (II) loaded EHL-NS (Hg/EHL-NS) was recorded to clarify the adsorption mechanism. As shown in Fig. 5, the bands of $\mathrm{C}=\mathrm{S}$ and $\mathrm{C}-\mathrm{S}$ shifted to lower frequencies while the $\mathrm{N}-\mathrm{CS}_{2}$ vibration shifted to higher frequencies. This result reflected the chemical bindings of $\mathrm{Hg}(\mathrm{II})$ to $\mathrm{C}=\mathrm{S}$. The $\mathrm{C}-\mathrm{S}$ bond reduced the effects of electrostatic induction and enhanced the double bond characteristics of $\mathrm{N}-\mathrm{CS}_{2}$. While $-\mathrm{NH}$ groups may form complexes with $\mathrm{Hg}$ (II) (Caner et al. 2015), no prominent changes in -NH were observed, but they may have been obscured by the absorption bands of - $\mathrm{OH}$. In sum, a strong metal-ligand bond formed between $\mathrm{Hg}(\mathrm{II})$ and the soft nitrogen and sulfur.

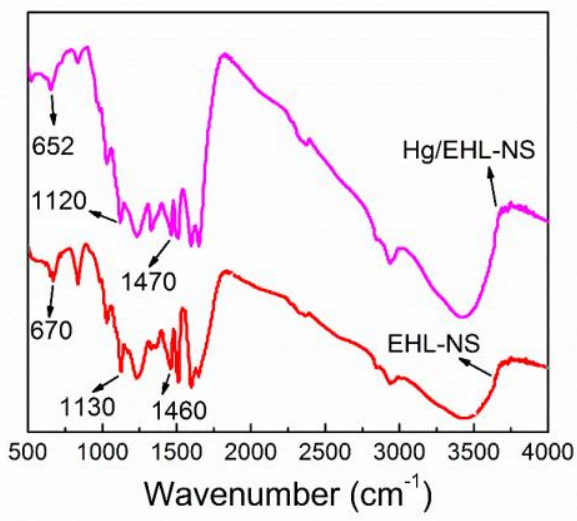

Fig. 5. FTIR spectra of EHL-NS and Hg/EHL-NS

\section{CONCLUSIONS}

1. An enzymatic hydrolysis lignin (EHL) derived polymer with soft nitrogen and sulfur (EHL-NS) was successfully synthesized.

2. The EHL-NS showed an enhanced antioxidant activity (IC50 $=25 \mu \mathrm{g} \mathrm{mL}^{-1}$ ) and a higher adsorption capability toward $\mathrm{Hg}(\mathrm{II})\left(Q_{\mathrm{e}}=180 \mathrm{mg} / \mathrm{g}, 25^{\circ} \mathrm{C}\right)$ than other naturalbased adsorbents.

3. The multi-functionality of EHL-NS was due to the incorporation of soft donors.

4. EHL is a low-cost and environmentally friendly material, and it has great potential as an antioxidant and for adsorption applications. 


\section{ACKNOWLEDGMENTS}

The authors are grateful for the support of the National Natural Science Foundation of China, Grant. No. 21464002, and Guangxi Natural Science Foundation (No. 2015GXNSFBA139215, 2016GXNSFAA380329, 2016GXNSFGA380003).

\section{REFERENCES CITED}

Anagnostopoulos, V. A., Manariotis, I. D., Karapanagioti, H. K., and Chrysikopoulos, C. V. (2012). "Removal of mercury from aqueous solutions by malt spent rootlets," Chemical Engineering Journal 213, 135-141. DOI: 10.1016/j.cej.2012.09.074

Bicak, N., Sherrington, D. C., and Senkal, B. F. (1999). "Graft copolymer of acrylamide onto cellulose as mercury selective sorbent," Reactive \& Functional Polymers 41(13), 69-76. DOI: 10.1016/s1381-5148(99)00021-8

Bugg, T. D. H., and Rahmanpour, R. (2015). "Enzymatic conversion of lignin into renewable chemicals," Current Opinion in Chemical Biology 29, 10-17. DOI: 10.1016/j.cbpa.2015.06.009

Caner, N., Sar1, A., and Tüzen, M. (2015). "Adsorption characteristics of mercury(II) ions from aqueous solution onto chitosan-coated diatomite," Industrial \& Engineering Chemistry Research 54(30), 7524-7533. DOI: 10.1021/acs.iecr.5b01293

Freundlich, H. M. F. (1906). "Over the adsorption in solution," Journal of Physical Chemistry 57, 385-470.

Ge, Y., Xiao, D., Li, Z., and Cui, X. (2014). "Dithiocarbamate functionalized lignin for efficient removal of metallic ions and the usage of the metal-loaded bio-sorbents as potential free radical scavengers," Journal of Materials Chemistry A 2(7), 2136-2145.

Kundu, S. K., and Bhaumik, A. (2016). "Novel nitrogen and sulfur rich hyper-crosslinked microporous poly-triazine-thiophene copolymer for superior $\mathrm{CO}_{2}$ capture," ACS Sustainable Chemistry \& Engineering 4(7), 3697-3703. DOI: 10.1021/acssuschemeng.6b00262

Langmuir, I. (1918). "The adsorption of gases on plane surfaces of glass, mica and platinum," Journal of the American Chemical Society 40(9), 1361-1403. DOI: $10.1021 / \mathrm{ja} 02242 \mathrm{a} 004$

Li, Z., Chen, J., and Ge, Y. (2017). "Removal of lead ion and oil droplet from aqueous solution by lignin-grafted carbon nanotubes," Chemical Engineering Journal 308, 809-817. DOI: 10.1016/j.cej.2016.09.126

Li, Z., Ge, Y., and Wan, L. (2015a). "Fabrication of a green porous lignin-based sphere for the removal of lead ions from aqueous media," Journal of Hazardous Materials 285(0), 77-83. DOI:10.1016/j.jhazmat.2014.11.033

Li, Z., Kong, Y., and Ge, Y. (2015b). "Synthesis of porous lignin xanthate resin for $\mathrm{Pb}^{2+}$ removal from aqueous solution," Chemical Engineering Journal 270(0), 229-234. DOI:10.1016/j.cej.2015.01.123

Li, Z., Ge, Y. (2011). "Extraction of lignin from sugar cane bagasse and its modification into a high performance dispersant for pesticide formulations," Journal of the Brazilian Chemical Society, 22 (10):1866-1871. DOI: dx.doi.org/10.1590/S010350532011001000006 
Monier, M. (2012). "Adsorption of $\mathrm{Hg}^{2+}, \mathrm{Cu}^{2+}$ and $\mathrm{Zn}^{2+}$ ions from aqueous solution using formaldehyde cross-linked modified chitosan-thioglyceraldehyde Schiff's base," International Journal of Biological Macromolecules 50(3), 773-781. DOI: 10.1016/j.ijbiomac.2011.11.026

Qin, L., Ge, Y., Deng, B., and Li, Z. (2017). "Poly (ethylene imine) anchored lignin composite for heavy metals capturing in water," Journal of the Taiwan Institute of Chemical Engineers 71, 84-90. DOI: 10.1016/j.jtice.2016.11.012

Rocha, C. G., Zaia, D. A. M., Alfaya, R. V. d. S., and Alfaya, A. A. d. S. (2009). "Use of rice straw as biosorbent for removal of $\mathrm{Cu}(\mathrm{II}), \mathrm{Zn}(\mathrm{II}), \mathrm{Cd}(\mathrm{II})$ and $\mathrm{Hg}$ (II) ions in industrial effluents," Journal of Hazardous Materials 166(1), 383-388. DOI: 10.1016/j.jhazmat.2008.11.074

Salanti, A., Zoia, L., Orlandi, M., Zanini, F., and Elegir, G. (2010). "Structural characterization and antioxidant activity evaluation of lignins from rice husk," Journal of Agricultural and Food Chemistry 58(18), DOI: 1004910055.10.1021/jf102188k

Thakur, V. K., Thakur, M. K., Raghavan, P., and Kessler, M. R. (2014). "Progress in green polymer composites from lignin for multifunctional applications: A review," ACS Sustainable Chemistry \& Engineering 2(5), 1072-1092. DOI: 10721092.10.1021/sc500087z

Vieira, R. S., and Beppu, M. M. (2006). "Dynamic and static adsorption and desorption of $\mathrm{Hg}(\mathrm{II})$ ions on chitosan membranes and spheres," Water Research 40(8), 17261734. DOI: 10.1016/j.watres.2006.02.027

Article submitted: May 21, 2017; Peer review completed: July 15, 2017; Revised version received and accepted: August 7, 2017; Published: August 21, 2017.

DOI: 10.15376/biores.12.4.7341-7348 